GHANA JOURNAL OF DEPARTMENT OF HEALTH, PHYSICAL EDUCATION AND RECREATION, SPORTS AND DANCE (GJOHPERSD)

Volume 10, Year 2017

A JOURNAL OF THE DEPARTMENT OF HEALTH, PHYSICAL EDUCATION AND RECREATION (HPER)

UNIVERSITY OF CAPE COAST

GHANA, WEST AFRICA 


\title{
EFFECT OF SHORT TERM CONSUMPTION OF ENERGY DRINK ON PHYSIOLOGICAL RESPONSES AND PHYSICAL PERFORMANCE VARIABLES OF ATHLETES IN UCC
}

\section{Yayra Kluboito* Joseph Babalola \& Omoniyi M. Moses}

Department of Health Physical Education and Recreation, University of Cape Coast, Ghana. Email: ykluboito@gmail.com*

Department of Human Kinetics and Health Education, University of Ibadan, Ibadan, Nigeria

Department of Exercise and Sports Science, Kwame Nkrumah University of Science and Technology, Kumasi, Ghana.

\begin{abstract}
Current research has shown varied results when comparing the effects of energy drink on anaerobic exercise measures. Athletes in Ghana have been using energy drink but hardly has any research been conducted on the effect this pre-exercise consumption has on their physical performance. The purpose of this study was to find out the effects of short-term consumption of energy drink on some blood pressure, heart rate, agility, lower body strength and upper body strength of athletes of the University of Cape Coast. To ascertain this, participants were taken through performance tests in a pre-test and a post-test. The intervention in this study was the consumption of 250ml of energy drink. Forty-four athletes (Age: $22.32 \pm 2.81$ years, height: $167.2 \pm 9.83 \mathrm{~cm}$, weight: $61.12 \pm 8.01$ $\mathrm{kg})$. Paired sample t test results showed no significant effect of energy drink consumption on systolic blood pressure $(t=-0.78, p$ $=0.437)$, diastolic blood pressure $(t=-0.91, p=0.366)$, heart
\end{abstract}


Kluboito et al

rate $(t=-030, p=0.759)$ and lower body strength $(t=0.11, p=$ $0.916)$. However, there were significant changes in agility $(t=$ 5.42, $p=0.001)$ and upper body strength $(t=-2.79, p=0.008)$. In view of this, athletes, trainers, and coaches could consider recommending the use of energy drink as a pre-exercise supplement, especially in events involving agility and upper body strength.

Keywords: Energy drink, Agility, Strength, Athletes 


\section{Introduction}

Sports require that participants should possess an expected high level of physical and physiological fitness. This could be attributed to the fact that the demands of sports rely heavily on both the anaerobic and aerobic energy sources (Michael, Rooney \& Smith, 2008). Although different kinds of sports require different kinds of skills and fitness variables (Marchetti et al., 2015), the ability to perform effectively and efficiently as well as show skill mastery competence, cuts across all sports disciplines (Gaurav, Singh \& Singh, 2011). This gives the need for athletes to acquire appropriate skills, physical and physiological conditioning as well as psychological profile for excellence in their sports (Wang et al., 2013). Some athletes instead of adhering to proper training and conditioning practices, in their bid to perfect their skills resort to other means which include integrating into their training regimens, the consumption of ergogenic supplements (Alsunni, 2011). Among the performance enhancers used by athletes is caffeine, an ingredient often consumed in the form of energy drinks (Salinero et. al., 2014).

Although the concept of 'energy drinks' has been defined in several concise complex ways, Heckman, Sherry and Gonzalez de Mejia (2010) simply defined energy drinks as beverages that contain besides calories, caffeine in combination with other presumed performance enhancing ingredients such as taurine, herbal extracts and B vitamins. Caffeine, the main 'energy' ingredient in energy drinks is a pharmacologically active substance and despite extensive research, its effects and health consequences still form the subject of ongoing debate (Finnegan, 2003, Committee on Nutrition and the Council of Sports Medicine and Fitness, 2011, Sengpiel et al, 2013). When caffeine is absorbed in the body, it stimulates the sympathetic nervous system and results in a rise in plasma catecholamine that allows the body to adapt to the stress created by physical exercise (An, Park, \& Kim, 2014).

Paddock (2008) reported that the most widely used medicinal ingredient in energy drinks, apart from caffeine, is the 
amino acid taurine. The supplementation of the diet with taurine is known to have many cardiovascular benefits (Militante, \&Lombardini, 2004). Various physiological functions have been attributed to taurine, among them are osmoregulation, calcium modulation and anti-oxidation. However, much still has to be understood about the role that taurine plays in the maintenance of life and normal function. In spite of this, the taurine has been promoted as the energy drink industry as a secret potent ingredient despite the controversy surrounding the ingredient. (Aggarwal, Mishra, Crochet, Sirimanna, \& Darzi, 2011).

Various researches have been done on different variables to either prove or disprove the ergogenic capability of energy drinks. Carvajal-Sancho and Moncada-Jimenez in 2005 investigating the acute effects of an energy drink on the Physical and Cognitive performance of male athletes found no significant changes in the physical and cognitive variables when comparing energy drink, a placebo and control conditions. However, significant pre-to posttest improvements in strength and power were found regardless of the experimental condition. Contrary to this finding, Alsunni (2011) stated that caffeine has an effective ergogenic agent by delaying fatigue and increasing time to exhaustion during endurance exercise but its efficacy as an ergogenic aid during anaerobic exercise and strength and power events is limited.

There is a rising curiosity of individuals on the effect of energy drinks on physical performance especially in a country like Ghana as television commercials make consumption look really appealing to the general public and athletes (Buxton and Hagan, 2012). Advertising for these products typically features images conjuring great muscle power and endurance.As a result of this phenomenon, there has been the need to investigate into this area in the country. Empirical research on energy drink consumption and the effects amongst Ghanaian populations has been scanty. However, the habit of consuming energy drink to enhance performance appears to be slowly becoming a part of the exercise regimens of most physically active person. 
Effect of Short term Consumpion of Energy drink on physiological responses and Physical performance variables of Athletes

In a research conducted on Ghana University Student athletes by Buxton and Hagan (2012), most of the participants $(62.2 \%)$ reported consuming at least one can of energy drink in a week. The respondents who drank energy drinks indicated that they did so to replenish lost energy after training or a competition, to provide energy and fluids to the body, to improve performance and to reduce fatigue. Again, Nti, Pecku and Opare-Obisiw (2014), reported that $91.0 \%$ of university students use energy drinks to help them study and also reduce fatigue. Even though $21.0 \%$ of these participants were aware of and had experienced side effects including stomach pains, headaches, and increased heart beats, they still continue to consume energy drinks neglecting future side effects such as chronic diseases (Seifert, Schaechter, Hershorin, \&Lipshultz, 2011). Babu, Church and Lewander (2008) reported that energy drinks are often mistaken for sports drinks, whose primary purpose is rehydration in the event of exercise or fluid loss.

Experiments conducted on the effects of energy drink on physical performance have been in the laboratory setting under very controlled conditions. Meanwhile, athletes and other physically active persons who consume these energy drinks however work in the real-world setting. This has brought about the need to conduct an experiment on the field to examine these effects under conditions that are as close as possible to the real world setting amongst a section of Ghanaian population which has come to accept the practice of consuming energy drinks with the aim of gaining extra energy for performance.

The purpose of this study was to examine the effect of short-term consumption of energy drink on physiological variables (blood pressure and heart rate) and physical performance variables (agility, upper body and lower body strength). For this reason, hypotheses were tested to ascertain the effect of short-term consumption of energy drink on physiological responses and physical performance variables. 
Kluboito et al

\section{Methodology}

The study was conducted using the one group pre-test post-test experimental research design and was conducted on the field for the sake of ecological validity since the field provides a setting which is close enough to the real world setting and conditions under which persons consume and use energy drinks for performance enhancement. Forty-four (44) athletes with ages ranging from $18-33(\mathrm{M}=22.32, \mathrm{SD}=2.81)$ participated in the study. The permissions of the participants were sought with an informed consent. Measures of height (131-188, $\mathrm{M}=167.2, \mathrm{SD}=$ 9.83) and weight (43.4-80.4, $\mathrm{M}=61.12, \mathrm{SD}=8.01)$ were taken as demographic data.

Participants were asked to refrain from caffeine containing food 48 hours prior to the trial because the half-life of caffeine is about four to six hours (Graham, 2001). The participants were asked to put in maximal effort during the exercise tests as this was the only way the data collected would be a true representation of their performances and also inform the researcher if they felt uncomfortable at any point. Participants were informed that they could back out of the research at any time during the study if they did not feel up to it. Ethical clearance was sought from the Institutional Review Board (IRB) of the University of Cape Coast. The investigation was done without altering the participant's dietary routine. However, the participants fasted for a short while which was practically close to the length of fasting prior to a competition.

All measures were taken with the appropriate tools which have their own psychometric properties. Physical characteristics of height and weight were measured for each participant as demographics using the stadiometer and a weighing scale respectively. Blood pressure and heart rate were measured using a sphygmomanometer (The deluxe auto digital blood pressure monitor) and the physical performance variables were measured using the Illinois agility test, overhead medicine ball throw (upper body strength) and vertical jump test (lower body strength). Pilot testing was done to ascertain their working conditions and also to 
Effect of Short term Consumpion of Energy drink on physiological responses and Physical performance variables of Athletes find out what to expect in the main study. Data were collected from one group which went through two measures therefore the analysis was done by comparing means within the group. Paired sample t-test was used to find the difference in means of pre-test and post-test measurements of each test variables with $\mathrm{p}<0.05$.

\section{Test Procedure}

On arrival on the day of the experimental trial, the participants were briefed and the physical characteristics measured as well as physiological variables of heart rate and blood pressure. Participants were then taken through the performance tests (Illinois agility test, vertical jump test and overhead medicine ball throw). Treatment was administered and the participants relaxed for 60 minutes after which they warmed up and went into the post test.

The same treatment protocol was administered to all the participants as the experiment was a one group design. The volume of the energy drink administered was set at a dose of $250 \mathrm{ml}$ (one can) and was administered 60 minutes before the post-test measurements. This was informed by Paton, Lowe and Irvine (2010) who mentioned in their study that use of caffeinecontaining energy drinks containing lower doses of caffeine (1-3 $\mathrm{mg} / \mathrm{kg}$ body weight) is more practical due to their availability and minimal side effects. The experimental trial consisted of a warmup and stretch period, a pre-test protocol, intervention, rest, warm up, a post-tests protocol and a cool down. At the beginning of each post-test trial, the participants consumed $250 \mathrm{ml}$ of energy drink and waited for sixty (60) minutes before proceeding on to the posttests. The warm-up was about five minutes where the participants went through general warm-up exercises and then stretching. 
Kluboito et al

\section{Results}

Table 1- T-test analysis results for effect of energy drink on systolic physiological responses, agility, lower body strength and upper body strength.

\begin{tabular}{|c|c|c|c|c|c|}
\hline \multirow[t]{2}{*}{ Variable } & \multicolumn{2}{|c|}{ Mean (SD) } & \multirow[t]{2}{*}{$\mathrm{t}$} & \multirow[t]{2}{*}{ df } & \multirow{2}{*}{$\begin{array}{l}\text { Sig. (2 } \\
\text { tailed) }\end{array}$} \\
\hline & Pre-test & $\begin{array}{c}\text { Post- } \\
\text { test }\end{array}$ & & & \\
\hline $\begin{array}{l}\text { Systolic } \\
\text { blood } \\
\text { pressure }\end{array}$ & $\begin{array}{l}126.34 \\
(14.10)\end{array}$ & $\begin{array}{l}128.27 \\
(12.94)\end{array}$ & -0.78 & 43 & .437 \\
\hline $\begin{array}{l}\text { Diastolic } \\
\text { blood } \\
\text { pressure }\end{array}$ & $\begin{array}{c}75.72 \\
(16.06)\end{array}$ & $\begin{array}{c}78.15 \\
(13.44)\end{array}$ & -0.91 & 43 & .366 \\
\hline Heart rate & $\begin{array}{c}83.72 \\
(12.22)\end{array}$ & $\begin{array}{c}84.27 \\
(13.33)\end{array}$ & -0.30 & 43 & .759 \\
\hline Agility & $\begin{array}{l}18.88 \\
(1.73)\end{array}$ & $\begin{array}{l}18.46 \\
(5.42)\end{array}$ & 5.42 & 43 & .000 \\
\hline $\begin{array}{l}\text { Lower body } \\
\text { strength }\end{array}$ & $\begin{array}{c}45.75 \\
(11.29)\end{array}$ & $\begin{array}{c}45.65 \\
(11.46)\end{array}$ & 0.11 & 43 & .916 \\
\hline $\begin{array}{l}\text { Upper body } \\
\text { strength }\end{array}$ & $\begin{array}{c}5.25 \\
(1.57)\end{array}$ & $\begin{array}{c}5.52 \\
(1.62)\end{array}$ & -2.79 & 43 & .008 \\
\hline
\end{tabular}

$\mathrm{p} \leq 0.05$

There were no significant differences in physiological responses (heart rate, systolic and diastolic blood pressure) with significant values ( $\mathrm{p}$ values) of $.759, .437$. and .366 respectively. This result indicates that short term consumption of energy drink does not have any significant effect on systolic blood pressure. Therefore, the researcher failed to reject the null hypotheses. Again, there was not a significant difference in the results for pretest and post-test with a significant value of .916. This implies that the consumption of energy drink did not have a significant effect on lower body strength of the participants. Therefore, the researcher failed to reject the null hypothesis. But, there was a significant difference in the results for pre-test and post-test 
Effect of Short term Consumpion of Energy drink on physiological responses and Physical performance variables of Athletes measurements of agility and upper body strength with significant values of .000 and .008 respectively. This implies that the consumption of energy drink had a significant effect on agility running time of the participants. Therefore, the null hypotheses were rejected.

\section{Discussion}

According to Reissig et al. (2009), when caffeine enters the blood, it makes the body think it is in an emergency and the pituitary gland initiates the body's fight or flight response by releasing adrenaline. This hormone makes the heart beat faster. Keeping this in mind, significant change in the heart rate of the participants after the consumption of the energy drink was expected. This outcome could be associated with the amount of energy drink $(250 \mathrm{ml})$ that was consumed in this study and caffeine content (80mg).

The results again could be due to the fact that the participants were trained athletes with improved physiological variables. The warm up, the exercise tests and the intervention together before the post-test were enough to cause changes in the systolic blood pressure but this increase was statistically significant. The performance tests were explosive and of short duration and so elevations in heart rate and blood pressure might not have been eminent. During dynamic exercise after the ingestion of energy drink, blood pressure, especially the systolic blood pressure could be elevated, but the change not being statistically significant could be linked to the quantity of energy drink ingested (Daniels, Mole, Shaffrath \& Stebbins, 1998).

Contrary to this finding, caffeine was found to have caused a significant increase in the mean heart rate after 60 minutes of ingestion in twenty male volunteers in a study by Geethavani, Rameswarudu and Rameshwari Reddy (2014). Also, there was a significant difference in the systolic blood pressure recorded in the study (Caffeine caused significant increase in the mean systolic blood pressure (60 minutes' post ingestion) from 116.6 to 128.3 $\mathrm{mmHg}$ as compared to placebo conditions. The mean rate increased from 72.9 to $77.3 \mathrm{Bpm}$ in test group (no change was 
observed in control group). Caffeine again caused significant increases in systolic blood pressure (SBP) (20 and 40 min post ingestion) and maximal arterial pressure (MAP) (40 min post ingestion) compared with placebo conditions (Daniels, Mole, Shaffrath \& Stebbins, 1998). Furthermore, no statistical interaction was found between the effects of caffeine and exercise on blood pressure. Also, in a study by Goldstein et al. (2010), diastolic blood pressure and heart rate were unaffected by caffeine. Systolic blood pressure was however significantly greater in post-exercise with caffeine $(\mathrm{p}<0.05)(116.8 \pm 5.3 \mathrm{mmHg}$ vs. $112.9 \pm 4.9$ $\mathrm{mmHg}$ ) in a study by Goldstein et al. (2010). All these studies have shown contradictory effects of caffeine and energy drink on physiological responses during exercise. Treatments in these studies were administered between thirty to sixty minutes' post exercise similar to this study and most other studies out there (Dawes et al., 2014, Stojanovic et al., 2011, Del Coso et al., 2012).

However similar to this study, an independent study by Apatov et al. (2011), in which they investigated the physiological effects of 5-hour energy drink on regular consumers, diastolic blood pressure was found not to be statistically affected by the consumption of the energy drink. Consistent with this data is a study by Daniels et al (1998) which also found that the magnitude of caffeine induced increases in resting and exercise diastolic blood pressure were not statistically different from respective control conditions. Again, in a study by Goldstein et al. (2010), diastolic blood pressure was unaffected by the consumption of caffeine.

Polinski et al (2011) in their study on the analysis of correlation between heart rate and blood pressure found correlations between the two variables, but this correlation was found to be in-consistent and varied from measurement to measurement. It is therefore understandable that there was a no significant change in the heart rate and blood pressure after the intervention. An et al. (2014) in the conclusion of their study stated that low dose caffeine produces no particular difference in heart rate at rest. In this study however, the heart rate was not measured at rest after the consumption of the energy drink indicating that 
Effect of Short term Consumpion of Energy drink on physiological responses and Physical performance variables of Athletes there could be a significant change when the heart rate is measured after exercise. The inconsistency in the literature regarding the changes that caffeine and energy drink causes in heart rate and blood pressure still continues as the results from this study adds to the negative findings that already exist. Nti et al. (2014) in their study had reported that $75 \%$ of the participants had increased heart rates as a result of the consumption of energy drinks. These participants were not athletes unlike the participants of this study, nor did they report that they felt this after going through physical activity.

The physical performance variable agility has been sparingly investigated into when it comes to investigations into the effects of energy drink on the performance variables. The above result implies that agility was a $100 \%$ affected by the consumption of energy drink. Variables which are close to agility that is including the components of agility (speed and change of direction) have been investigated into. In Del Coso et al.'s (2012) research into the effect of caffeine containing energy drink on simulated soccer performance, they investigated as part of their study the effect of Red Bull energy drink on the number of sprints run by their participants in a simulated soccer performance. These sprints in the game could be related to agility as running pattern in soccer involves change of direction. The mean running speed during the speed test in this study was also increased as a result of the consumption of the energy drink as against the placebo given. Contrary to the results for this study and the study by Del Coso et al., energy drink treatment did not have any significant effect on reactive sprint test of participants in a study to investigate the effects of a pre-workout energy drink on measures of physical performance buy Dawes et al. (2014). Similarly, a pre-workout consumption of energy drink by participants in another study by Paez et al. (2014) did not cause any significant change in the time taken to complete the test. Issues about reaction time could also be considered in this discussion of agility test results as the participants had to respond to the stimuli for the start in order to make a good time on the agility test. 
It was reported in a study by Duvnjak-Zaknich et al. (2011), that there is improved interpretation and response to stimuli of an individual after ingesting caffeine. Their study was to investigate the effect of caffeine on reactive agility time when fresh and fatigued, and faster times were recorded for the reactive agility tests were consistently faster after the ingestion of caffeine. A similar study conducted by Jordan (2012) who tried to find out of reactive agility through the dominant and non-dominant side and found that caffeine supplementation significantly improved players' reaction times to their non-dominant side. This goes to imply that energy drink has been found to improve agility in most studies even though there are still some studies in which agility in whichever form it was had been unaffected by pre-workout energy drink consumption.

Lower body strength was tested in this study using the vertical jump test. A statistical significance value of 0.458 , the vertical jump test showed no significant difference after the consumption of energy drink. This implies that the energy drink treatment had no effect on the lower body strength (vertical jump). Similarly, energy drink treatment did not enhance vertical jump performance in the participants of the study by Dawes et al. (2014). Del Coso et al. (2012) also found similar results in their study. Stojanovic et al. (2011), had also tested lower body strength using vertical jump and analyses of variance conducted revealed no differences between placebo and supplement group in vertical jump. Contrary to the results from this study however, increments in the mean jump height of participants after ingesting energy drink in comparison to a placebo was found in a study by Del Coso et al. (2012).

Upper body strength was found to be significantly affected by the short-term consumption of energy drink. This result could be attributed to the age and metabolism of the athletes. Upper body strength in most researches have been tested using other activities such as bench press and hand grip strength test. In Eckerson et al.'s (2011) study, they tested upper body strength using bench press. Participants had to do a 1RM bench press after consuming energy drink and no effect was found. Stojanovic et al. (2011) tested hand 
Effect of Short term Consumpion of Energy drink on physiological responses and Physical performance variables of Athletes grip in their study the results also showed no significant improvements in performance. Similarly, a moderate dose of caffeine was found to enhance strength performance of resistance trained women in a one repetition maximum barbell bench press test in a study by Goldstein et al. (2010). These results are in agreement with the result of this study. These results are in disagreement with Astorino et al. (2008) as the authors of that investigation reported no significant increase in upper body strength in resistance trained males after consuming $6 \mathrm{mg} / \mathrm{kg}$ of caffeine. Similar to the overhead medicine ball throw which was used in this study to test for upper body strength, ballistic bench throw was used by Krammerer et al. (2012) and the caffeine ingested caused a significant increase in the peak performance, peak power and peak velocity.

The outcomes of research investigations that have examined the effects of caffeine ingestion on strength have been inconsistent and most administered caffeine in capsule forms. For this study however, the caffeine was consumed in one $250-\mathrm{mL}$ serving of energy drink containing $80 \mathrm{mg}$ of caffeine. Despite the fact that the caffeine dosage for this study was relatively low, there still were significant changes in agility and upper body strength after the ingestion of energy drink. Lower body strength on the other hand was not increased with the ingestion of the energy drink.

The purpose for this study was to conduct research under condition that are as close to what the Ghanaian athlete usually does hence the reason for this dosage and as Paton et al. (2010) had said, use of caffeine-containing energy drinks containing lower doses of caffeine (1-3 mg/kg body weight) is more practical due to their availability and minimal side effects. Therefore, the athletes' usual choice of caffeine intake was considered for this study. This dosage and the conditions under which the performance test was conducted could be a great influence to the outcomes of the study. 


\section{Conclusion}

All the physiological measurements were not significantly affected by the ingestion of energy drink. These results may be applied to alter pre-exercise consumption of energy drink. Again, $250 \mathrm{ml}$ of energy drink was not enough to cause significant elevations in the blood pressure and heart rates of the athletes implying that this dosage may be a safe dosage to use for short term supplementation with minimal physiological effects. For the physical performance variables, significant changes were recorded after the ingestion of energy drink in the agility and upper body strength but not the lower body strength.

Results of this study suggest that healthy athletes do experience performance benefits from short term energy drink supplementation when consumed before performing short term exercise in this case, agility and upper body strength exercise. However, this short-term supplementation does not have performance benefits on lower body strength. While athletes could have some differences in how their bodies are affected by the short-term consumption of energy drink, it has no significant effects on their physiological responses. Therefore, athletes who consume energy drink for a short term in competition could be said to have no advantage over their fellow athletes who compete without energy drink for events in which lower body strength is predominant therefore, they should reconsider as the short-term consumption of energy drink does not have significant effect on lower body strength.

Trainers and coaches could consider recommending the use of the commercially available energy drink as a short-term preexercise supplement, especially in events in which agility and upper body strength are key. Also, athletes who wish to enhance their performances using energy drink can do so knowing that the short-term consumption of energy drink does not have significant effect on their physiological responses (blood pressure and heart rate) during performance. 
Effect of Short term Consumpion of Energy drink on physiological responses and Physical performance variables of Athletes

\section{References}

Aggarwal, R., Mishra, A., Crochet, P., Sirimanna, P., \& Darzi, A. (2011). Effect of caffeine and taurine on simulated laparoscopy performed following sleep deprivation. $\mathrm{Br} J$ Surg., 98, 1666-1672

Alsunni, A. A., (2011). Are energy drinks physiological? Pak $J$. Physiol 7(1).

An, S. M., Park, J. S., \& Kim, S. H., (2014). Effects of energy drink dose on exercise capacity, heart rate recovery and heart rate variability after high intensity exercise. J Exerc. Nutr. Biochem., 18(1), 31-39.

Apatov, D., Eberwein, A., Klein, T., \& Schroeder, S. (2011). The physiological effects of 5- Hour energy drink. Unpublished Independent study.

Astorino, T. A., Rohmann, R. L., Firth, K., \& Kelly, S. (2008). Effect of caffeine ingestion on one-repetition maximum muscular strength. European Journal of Applied Physiology, 102, 127-132.

Babu, K. M., Church, R. J., \& Lewander, W., (2008). Energy drinks: The new eye-opener for adolescents. Clinical Pediatrics Emergency Medicine, 9, 35-42.

Buxton, C., \& Hagan, J. E. (2012). A survey of energy drinks consumption practices among student-athletes in Ghana: Lessons for developing health education intervention programmes. Journal of the International Society of Sports Nutrition, 9, 9-12.

Carvajal-Sancho, A., \& Moncada-Jimenez, J. (2005). The acute effect of an energy drink on the physical and cognitive performance of male athletes. Kinesiologia Slovenica, 11(2), 5-16.

Committee on Nutrition and the Council on Sports Medicine and Fitness. (2011). Clinical report - sports drinks and energy drinks for children and adolescents: Are they appropriate? Pediatrics, 127(6), 1182-89.

Daniels, J. W., Mole, P. A., Shaffrath, J. D., \& Stebbins, C. L. (1998). Effects of caffeine on blood pressure, heart rate, 
Kluboito et al

and forearm blood flow during dynamic leg exercise. Journal of Applied Physiology, 85(1), 154-159.

Dawes, J. J., Campbell, B. I., Ocker, L. B., Temple, D. R., Jeremy

G. Carter, J. G., \& Brooks, K. A. (2014). The effects of a pre-workout energy drink on measures of physical performance. International Journal of Physical Education, Fitness and Sports, 3(4), 122-131.

Del Coso J., Muñoz-Fernández, V. E., Muñoz, G., FernándezElías, V. E., Ortega, J. F., Hamouti, N., Barbero, J. C., \& Muñoz-Guerra, J. (2012). Effects of a caffeine-containing energy drink on simulated soccer performance. PLoS One, 7(2): e31380. doi:10.1371/journal.pone.0031380.

Del Coso, J., Salinero, J. J., González-Millán, C., Abián-Vicén, J., \& Pérez-González, B. (2012). Dose response effects of a caffeine-containing energy drink on muscle performance: A repeated measures design. Journal of the International Society of Sports Nutrition, 9, 21-25.

Duvnjak-Zaknich, D. M., Dawson, B. T., Wallman, K. E., \& Henry, G. (2011). Effect of caffeine on reactive agility time when fresh and fatigued. Med. Sci. Sports Exerc., 43(8), 1523-1530.

Eckerson, J., Bull, A., Moore, G., Baechle, T., Yee, J., Egan, S., Fischer, C., O'Brein, D., \& Pulverenti, T. (2011). The effect of sugar free energy drinks on upper body strength and muscular endurance in males. Journal of Strength \& Conditioning Research, 25 retrieved from www.journals.lww.com on 16/12/2015.

Finnegan, D. (2003). The health effects of stimulant drinks. Nutrition Bulletin, 28(2), 147-155.

Gaurav, V., Singh, A., \& Singh, S. (2011). Comparison of physical fitness variables between individual games and team games athletes. Indian Journal of Science and Technology, 4(5), 547-549.

Geethavani, G., Rameswarudu, M., \& Rameshwari Reddy, R. (2014). Effect of caffeine on heart rate and blood pressure. International Journal of Scientific and Research Publications, 4(2), 1-3. 
Effect of Short term Consumpion of Energy drink on physiological responses and Physical performance variables of Athletes

Goldstein, E., Jacobs, P. L., Whitehurst, M., Penhollow, T., \& Antonio, J. (2010). Caffeine enhances upper body strength in resistance-trained women. Journal of the International Society of Sports Nutrition, 7(18), 1550-2783.

Graham, T. E. (2001). Caffeine and exercise: Metabolism, endurance and performance. Sports Medicine, 31, 785-807.

Heckman, M. A., Sherry, K., \& Gonzalez de Mejia, E. (2010). Energy drinks: An assessment of their market size, consumer demographics, ingredient profile, functionality and regulations in the United States. Comprehensive Review in Food Science and Food Safety (CRFSFS), 9, 303-317.

Kammerer, E., Krings, T., Wojton, S., Scheckel, E., Kuklinski, E., Jacobs, K., Homan, C., Veldhuizen, J., Siegle, S., Wright, A., McCann, M., Anderson, D., \& Lowery, L. (2012). The effects of a caffeine-containing beverage on muscle explosiveness during ballistic bench throws. Journal of the International Society of Sports Nutrition, 9(1), 15-21.

Jordan, J. B. (2012). Caffeine supplementation and reactive agility in elite youth soccer players. Unpublished thesis.

Marchetti, R., Forte, R., Borzacchini, M., Vazon, S., Tomporowski, P. D., \& Pesce, C. (2015). Physical and motor fitness sports skills and executive function in adolescents: A moderated prediction model. Psychology, 6, 1915-1929.

Micheal, J. S., Rooney, K. B., \& Smith, R. (2008). The metallic demands of Kayaking: A review. Journal of Sports Science and Medicine, 7, 1-7.

Militante, J. D., \& Lombardini, J. B. (2004). Dietary taurine supplementation: Hypolipidemic and antiatherogenic effects. Nutrition Research, 24, 787-80.

Nti, C. A., Pecku, E., \& Opare-Obisaw, C. (2014). Energy Drink Consumption among University Students in Accra, Ghana. Nature and Science., 12(8), 85-89.

Paton, C. D., Lowe, T., \& Irvine, A. (2010). Caffeinated chewing gum increases repeated sprint performance and augments 
Kluboito et al

increases in testosterone in competitive cyclists. European Journal of Applied Physiology, 110(6), 1243-1250.

Paddock, R. (2008). 'Energy drinks' implication for student athletes and athletic departments. Sports Digest, 16(4), $1558-6448$.

Poliński, A., Kot, J., \& Meresta, A. (2011). Analysis of correlation between heart rate and blood pressure. Proceedings of the Federated Conference on Computer Science and Information Systems, 2, 417-420.

Reissig, C. J., Strain, E. C., \& Griffiths, R. R. (2009). Caffeinated energy drinks: A Growing Problem. Drug Alcohol Dependence, 99, 1-10.

Salinero, J. J., Lara, B., Abian-Vicen, J., Gonzalez-Millán, C., Areces, F., Gallo-Salazar, C., Ruiz-Vicente, D., \& Del Coso, J. (2014). The use of energy drinks in sport: perceived ergogenicity and side effects in male and female athletes. British Journal of Nutrition, 112(09), 1494-1502.

Seifert, S. M., Shaechter, J. L., Hershorin, E. R., \& Lipshultz, S. E. (2013). Health effects of energy drinks on children, adolescents and young adults. Pediatrics, 127(3), 511-528.

Stojanovic, M. D., Stojanovic, M. D., Kanostrevac, K., Veljovc, Dragoljb, V., Medjedovc, B., \& Ostojc, S. M. (2011). The effects of pre-exercise high energy on exercise performance in physically active men and women. Scientific Research: Advances in Physical Education, 1(1), 1-5.

Wang, C., Chang, C., Liang, Y., Shih, C., Chui, W., Tseng, P., Hung, D. L., Tzeng, O. J. L., Muggleton, N. G., \& Juan, C. (2013). Open vs closed skill sports and the modulation of inhibitory control. PloS One, 8(2), e55773, http://doi.org/10.1371/journal.pone.0055773. 